\title{
Husbandry stress during early life stages affects the stress response and health status of juvenile sea bass, Dicentrarchus labrax
}

\author{
S. Varsamos ${ }^{b}$, G. Flik ${ }^{b}$, J.F. Pepin ${ }^{a}$, S.E. Wendelaar Bonga ${ }^{b}$ and G. Breuil ${ }^{a,{ }^{*}}$
}

a IFREMER, Laboratoire de Recherche Piscicole de Méditerranée, DRV/RA, Chemin de Maguelone, 34250 Palavas-les-Flots, France

b Department of Animal Physiology, Radboud University Nijmegen, Toernooiveld 1, 6525 ED

Nijmegen, The Netherlands

Received 5 January 2005; revised 4 March 2005; accepted 28 April 2005. Available online 14 June 2005.

*: Corresponding author : gilles.breuil@ifremer.fr

\begin{abstract}
:
In aquaculture management it is important to establish objective criteria to assess health and welfare of the fish. Here we show that European sea bass (Dicentrarchus labrax) confronted with husbandryassociated stress (tank cleaning, i.e. scrubbing, and water temperature variation) during early life stages show poorer survival and disease resistance as juveniles. We evaluated several parameters for stress (plasma cortisol, glucose and lactate, hydromineral status), growth performance, the immune response (plasma IgM levels) and the effects of a nodavirus challenge. Principal component analysis allowed the establishment of a stress panel including plasma cortisol, osmolality, IgM levels and weight. Sea bass juveniles reared during early life in high and constant temperature perform best in terms of stress-related parameters assessed by principle component analysis. Variable water temperature triggers dramatic changes in plasma cortisol, osmolality, IgM levels, body weight and susceptibility to nodavirus that suggest a strong and prolonged activation of the HPI axis. Scrubbing induces some disturbances typical for mild short-term, acute stress, viz. increased plasma osmolality and decreased IgM levels, but does not affect plasma cortisol, growth or susceptibility to nodavirus of sea bass. Our data fit well with the concept of allostasis. We discuss the relevance of our work for sea bass aquaculture.
\end{abstract}

Keywords: Stress; Allostasis; Health; Welfare; Temperature; Scrubbing; Nodavirus challenge; Dicentrarchus labrax 


\section{Introduction}

Fish in culture are exposed to various husbandry-related acute (e.g. handling) and chronic (e.g. poor water quality, confinement) stressors. The physiological response to stressors has received great attention over the last decades and a great amount of data has attempted to complete, refute or replace Selye's [1] "non-specific" stress concept, also known as the "General Adaptation Syndrome", which describes an alarm, a resistance and an exhaustion stage (reviews in [2-6]). More recently, the concept of allostasis has been introduced to explain constancy through change. Allostasis is a fundamental process through which organisms actively adjust to both predictable and unpredictable events [7]. An allostatic state refers to altered and sustained activity levels of the primary mediators (e.g. glucocorticosteroids) in response to a stressor. The cumulative result of an allostatic state is allostatic load. Within limits an organism can cope with and adapt to or tolerate stressors to keep homeostasis. However, when the system is not dealing well with the disturbing factor the increased allostatic load results in allostatic overload [7].

Recently, the health and well-being of animals farmed under intensified management practices have been the focus of a large public debate $[8,9]$. It is becoming increasingly clear that fisheries managers and associated scientists need to establish criteria by which aquatic animals' health and well-being are objectively defined, and in accordance with the European Union's guidelines for future aquaculture developments with regards to welfare, quality and health of reared species.

The European sea bass (Dicentrarchus labrax) is a marine, euryhaline teleost with important socio-economic value for the Mediterranean aquaculture industry. This species has, for those reasons received ample scientific interest 
over the last 35 years, but aquaculture related stress appears to have major negative impacts on the culture of this fish. Fundamental research into the stress responses of this species could greatly improve production and avoid disease susceptibility and massive mortality often observed (review in [10]).

In the present work we assessed the effect of early life stress associated with common husbandry stressors (scrubbing and temperature variations) on stress and health physiological parameters of Dicentrarchus labrax juveniles (8$22 \mathrm{~g}$ ). A bioassay based on nodavirus challenge was included to discriminate effects of husbandry stressors and different early life stress experiences on non-specific immune status of farmed fish. We analysed the data in a multivariate statistical approach to test the relevance of physiological indicators currently employed to monitor health and stress in fish.

\section{Material and methods}

\subsection{Fish}

The fish used were offspring from seronegative (no nodavirus antibodies detectable in serum) females [11] reared in the Institut Français de Recherche et d'Exploration de la Mer (IFREMER) station at Palavas les Flots (France). Rearing from eggs to juveniles was performed in 500-L flow-through cylindroconical tanks. Eggs were allowed to hatch in natural seawater (38 \%o salinity; SW) at $14^{\circ} \mathrm{C}$. Until day 9 the larvae were not fed and submitted to $0 \mathrm{~h}$ light : $24 \mathrm{~h}$ dark;thereafter Artemia was provided as food. Photoperiod was gradually increased within three days up to $12 \mathrm{~h}$ light: $12 \mathrm{~h}$ dark. Light intensity was also gradually increased from 70 up to 450 lux during the larval rearing. Sixty-nine hours after hatching, water salinity was reduced to $25 \%$ by dilution with tap water and maintained at that level until day 50. Then salinity was 
gradually increased again to full-strength SW and maintained at that level until the end of the experiments. After weaning, fish were fed on commercial pellets (Aqualim) at a daily ration of $2 \%$ of the estimated wet weight.

\subsection{Stress parameters}

Two weeks after hatching fish were divided in six groups each placed in 500-L tanks. The following six parameters were applied.

Constant temperatures ( $\mathrm{T} 1$ and $\mathrm{T} 2$ ): One batch of fish was maintained at $17 \pm 1^{\circ} \mathrm{C}(\mathrm{T} 1)$. For a second batch the temperature was gradually increased to $23 \pm 1^{\circ} \mathrm{C}$ over a period of $24 \mathrm{~h}(\mathrm{~T} 2) . \mathrm{T} 1$ and $\mathrm{T} 2$ batches were reared under these conditions for six months.

Constant Temperatures and Scrubbing (S1 and S2): A third batch (S1) was kept at $17 \pm 1^{\circ} \mathrm{C}$ for three months and was exposed to scrubbing procedures at the same temperature during the next three months (scrubbing for $5 \mathrm{~min}$, three times per day). In the fourth batch (S2), temperature was gradually increased to $23 \pm 1^{\circ} \mathrm{C}$ (as for T2) and exposed to scrubbing as S1.

Variable Temperature (V1 and V2): The fifth batch (V1) was kept at $17 \pm 1^{\circ} \mathrm{C}$ and for the sixth batch (V2) temperature was gradually increased up to $23 \pm 1^{\circ} \mathrm{C}$ as for T2. These batches were kept under these conditions for three months. During the next three months on the fish were subjected to temperature changes from $17^{\circ} \mathrm{C}$ to $23^{\circ} \mathrm{C}$ and vice versa on alternate days.

\subsection{Sampling}

Feeding was stopped $24 \mathrm{~h}$ before sampling. At the end of the experiment 15 randomly taken fish from each treatment (T1, T2, S1, S2, V1, V2) were netted and transferred to small containers filled with SW at $4^{\circ} \mathrm{C}$. Sampling 
procedure for each tank did not exceed 10 min. From each fish two blood samples were taken by puncture from the caudal vessels. For one $(A) \mathrm{Na}_{2}$ EDTA was used as anticoagulant, for the other (B) no additives were added to prepare serum. After blood sampling the fish were quickly euthanised and weighed. Blood sample A was centrifuged (5 min at 9,000 g) and plasma stored frozen ($20^{\circ} \mathrm{C}$ ) until further analyses. Blood sample B was allowed to settle to obtain blood serum, which was frozen $\left(-20^{\circ} \mathrm{C}\right)$ until further analysis.

For each fish the stress- and health-related parameters listed below were measured. The sampling rank of the fish was considered as a variable. We considered three levels of rank for each treatment: samples 1 to 5 were designated rank 1, samples 6 to 10 rank 2 and samples 11 to 15 rank 3.

The size of the fish at sampling (8-17 gr) permitted only small plasma and serum samples (80 to $150 \mu \mathrm{l}$ ); consequently, a limited number of parameters could be assessed. For each fish indicators characteristic of three levels of the stress response (see below) have been considered.

\subsection{Stress parameters}

Cortisol. Plasma concentrations of cortisol (indicator of the primary stress response), expressed in $\mathrm{ng} / \mathrm{mL}$, were determined in duplicate by radioimmunoassay (RIA) according to Balm et al. [12]. The cortisol antibody used has marginal cross-reactivity with 11-deoxycortisol (5.9\%), cortisone acetate $(0.16 \%)$, cortisone $(2.6 \%)$ and $17 \alpha-\mathrm{OH}$-progesterone $(0.4 \%)$. The intraand inter-assay coefficients of variation were 3 and $5 \%$ respectively.

Plasma ions. After appropriate dilutions of the samples plasma $\mathrm{Na}^{+}, \mathrm{K}^{+}$ and $\mathrm{Cl}^{-}$levels (indicators of the secondary stress response), expressed in mM, 
were measured in a flame photometric Auto Analyser. The $\mathrm{Na}^{+} / \mathrm{Cl}^{-}$and $\left(\mathrm{Na}^{+}+\mathrm{K}^{+}\right) / \mathrm{Cl}^{-}$ratios were calculated and included in the statistical analysis.

Plasma lactate and glucose. Plasma concentrations of lactate and glucose (indicators of the secondary stress response), expressed in $\mathrm{mM}$, were determined with a pHOx Plus analyser (Nova Biomedical, The Netherlands).

Plasma osmolality. Osmolality (indicator of the secondary stress response), was measured on $30 \mu$ plasma samples by use of an automatic micro-osmometer (Autocal $13^{\circledR}$ Roebling) and expressed in mOsm. $\mathrm{kg}^{-1}$.

Body weight. Body weight at the end of the experiments was considered as a variable integrating long term effect of stressors on growth (tertiary stress response).

\subsection{Health}

$\operatorname{IgM}(E L I S A$ "IgM"). Serum IgM (indicator of the tertiary stress response) was quantified (in triplicate) by ELISA, according to Coeurdacier et al. [13].

\subsection{Nodavirus challenge}

\subsubsection{Virus collection}

The nodavirus strain was isolated from infected Dicentrarchus labrax reared in Mediterranean sea [14], and purified according to the method previously described $[15,11]$. The virus provided by William Starkey (Stirling University) was cultivated on Striped Snake (SSN-1) fish cell lines [16] and cell supernatants were harvested and titrated by the use of a dilution method developed within an earlier EU project (Nodavirus disease in culture marine fish in Europe: Contract FAIR CT 98-4036). They were stored frozen $\left(-20^{\circ} \mathrm{C}\right)$ until the infection experiments. 


\subsubsection{Seronegativity of challenged fish (ELISA "antibody")}

One week before challenge, blood samples were taken from all the fish (randomly) selected for virus challenge. Seronegativity was checked (in triplicates) on serum by using ELISA, according to Breuil \& Romestand [11].

\subsubsection{Infection experiments}

The first challenge involved 40 fish from each treatment (T1, T2, S1, S2, V1, V2). They were intramuscularly (IM) injected and placed in two different 50 L tanks (20 fish per duplicate tank). Each fish was inoculated with two injections of $0.2 \mathrm{~mL}$ of live nodavirus suspension $\left(4 \times 10^{9} \mathrm{PFU} \cdot \mathrm{mL}^{-1}\right)$ at two different sites and reared at $25^{\circ} \mathrm{C}$ for 21 days. Dead and affected fish (i.e. fish showing whirling disease) were counted daily, removed and sampled for nodavirus presence in brain by ELISA (see below: ELISA "antigen") and for detection of lesions by immunocytochemistry according to Peducasse et al. [17]. To test the effect of size on our experiments (Dicentrarchus labrax reared at higher temperatures grow faster), a second indentical infection experiment was performed on fish reared at the lower temperature (batches T1, S1) as soon as they had reached the mean size of the fish reared at the higher temperature (T2, S2). During virus challenge the effluent water was chlorine-treated by the use of an automated injection system (HYDROBOX M1, HYDROCHIM, France).

\subsubsection{Virus detection following challenge (ELISA "antigen")}

Brain tissue was removed from frozen fish, and homogenised with a hand-held micro potter (eppendorf). Homogenate was diluted 1:4 (w/w) with 0.5 $\%$ skimmed milk in phosphate buffered saline (PBS) pH 7.4. The supernatant obtained after centrifugation at $12800 \mathrm{~g}$ for 5 min was collected and stored at $20^{\circ} \mathrm{C}$. An homogenate made of a pool of 34 brains of seronegative fish served 
as negative control. Serial dilutions of purified nodavirus (195, 64, 21 and $7 \mathrm{ng}$. $\mathrm{mL}^{-1}$ ) in $0.5 \%$ skimmed milk-PBS were used as positive control. 34 seronegative sea bass brains were individualy analysed to calculate the cut off limit of the assay. The samples were analysed (in triplicates) by ELISA as described earlier [18-19], with some slight modifications. Endogenous peroxidase activity was blocked with $50 \mu \mathrm{l}$ of $0.5 \% \mathrm{H}_{2} \mathrm{O}_{2}$ for $15 \mathrm{~min}$. The immunoassays were carried out in triplicate and individual results were calculated using KcJunior software (BIO-TEK Instrument).

\subsection{Statistics}

Data were checked for normal distribution and equality of variance. When necessary, appropriate transformations were performed (e.g. log[cortisol]). A two step analysis was performed. The first step was a principle component analysis (PCA) for all data from all treatment groups (T1, T2, S1, S2, V1, V2). Subsequently, the second step consisted of statistical analysis of selected variables by means of MANOVA, with a significance limit of $P<0.05$. Tukey's post-test was chosen for multiple pair wise comparisons. Relative differences (in \%) in mean values of parameters (Table 2) between treatments were calculated as follows: 100x((higher value)-(lower value))/lower value).

The effect of the experimental treatments (T1, T2, S1, S2, V1, V2) on susceptibility to virus challenge was tested by two-way ANOVA following $\arcsin / \mathrm{n}^{1 / 2}$ transformation of the data [20], with significance set at $P<0.05$. Tukey's post-test was used for multiple pair wise comparisons. Considering the virus detection in the brain of challenged fish the results were analysed by the Bienaymé-Tchebitcheff inequality with a significance limit of $P<0.05$ [18]. 


\section{Results}

\subsection{Stress parameters}

Nine parameters were measured for each of the 90 fish from the six treatments (T1, T2, S1, S2, V1, V2). The results of the Principal Component Analysis (PCA) are summarized in Figure 1. The first three components (24, 26 and $22 \%$ for components 1,2 and 3 respectively) accounted for $72 \%$ of the variability of the data (Table 1).

The first component was related to ionic balance $\left(\mathrm{Na}^{+}, \mathrm{K}^{+}\right.$and $\left.\mathrm{Cl}\right)$ while the second was biologically consistent with "stress-related" variables (IgM, body weight, cortisol and osmolality). The variables associated with component 2 (Table 2A) were selected for further statistical analysis by MANOVA (see below). The third component was related to carbohydrate metabolism (glucose and lactate).

3.1.1 The effects of constant rearing temperature (treatments T1, T2), scrubbing (treatments S1, S2) and sampling rank on serum $\operatorname{lgM}$ concentration, plasma osmolality, plasma cortisol concentration and body weight (Table 3).

The sampling rank did not have any significant effect $(p=0.07)$ on the parameters considered in this analysis. Rearing temperature ( $\mathrm{S} 1+\mathrm{T} 1$ vs $\mathrm{S} 2+\mathrm{T} 2$, Table 2B) had a significant effect $(p<0.05)$ on all stress parameters considered. Cortisol was almost 4-fold and significantly higher (30 vs 10 ng.mL ${ }^{-1}:+398 \%$ ) $(\mathrm{p}<0.05)$; on the opposite, body weight ( 8.7 vs $22.5 \mathrm{~g})$, serum IgM content ( 0.54 vs $\left.2.1 \mathrm{mg} \cdot \mathrm{mL}^{-1}\right)$, and osmolality (352 vs $\left.362 \mathrm{mosm} \cdot \mathrm{kg}^{-1}\right)$ were lower $(\mathrm{p}<0.05)(-$ $158,-288$ and $-3 \%$ respectively) in fish reared at the low rearing temperature condition. Scrubbing (T1+T2 vs S1+S2, Table 2B) had a significant effect $(p<0.05)$ on two parameters. It induced a mild but significant $(p<0.05)$ increase 
in blood osmolality (350 vs 365 mosm. $\left.\mathrm{kg}^{-1}:+4 \%\right)$ and a significant $(\mathrm{p}<0.05)$ decrease (1.48 vs $1.14 \mathrm{mg} \cdot \mathrm{mL}^{-1}$ : $-30 \%$ ) in serum IgM content. No significant effect was found on plasma cortisol concentration (23 vs $17 \mathrm{ng} \cdot \mathrm{mL}^{-1}: \mathrm{p}=0.88$ ), or on weight (15.7 vs $15.6 \mathrm{~g}: \mathrm{p}=0.76)$.

\subsubsection{The effects of sampling rank and temperature conditions (constant,} and variable: V1, V2, T1 and T2) on serum IgM concentration, plasma osmolality, plasma cortisol concentration and body weight (Table 4).

The sampling rank had a significant effect on two of the parameters measured $(p<0.05)$. Plasma cortisol concentration was lower in the fish of rank 1 compared to fish of rank 2 ( $p<0.05)$, whereas no difference was found in cortisol between fish of rank 1 and fish of rank 3, neither between fish of rank 2 and those of rank $3(p=0.071)$. Fish of rank $1(15 \mathrm{~g})$ were significantly bigger $(+17 \%)$ than those of rank $3(12.4 \mathrm{~g})(\mathrm{p}<0.05)$. The weight of fish of rank 2 and 3 were not significantly different $(p=0.27)$. No significant effect of rank was found on plasma osmolality or serum IgM concentration.

Rearing temperature level $(\mathrm{V} 1+\mathrm{T} 1 \mathrm{vs} \mathrm{V} 2+\mathrm{T} 2$, Table $2 \mathrm{~B})$ had a significant effect $(p<0.05)$ on three of the parameters considered. Serum IgM concentration (0.64 vs $1.77 \mathrm{mg} \cdot \mathrm{mL}^{-1}$ ) and weight (9.9 vs $\left.17.6 \mathrm{~g}\right)$ were significantly $(p<0.05)$ higher in fish reared at higher temperature $(+176$ and +76 $\%$, respectively), whereas cortisol (113 vs $\left.81 \mathrm{ng} \cdot \mathrm{mL}^{-1}\right)$ was significantly $(p<0.05)$ higher in fish reared at the low temperature (+38\%). No significant effect of stable rearing temperature was found for plasma osmolality (378 vs 363 $\left.\operatorname{mosm} \cdot \mathrm{kg}^{-1}\right)$.

Daily (on alternate days) variation of temperature significantly $(p<0.05)$ affected all the parameters considered $(\mathrm{V} 1+\mathrm{V} 2$ vs $\mathrm{T} 1+\mathrm{T} 2$, Table $2 \mathrm{~B})$. Serum IgM concentration (0.93 vs $1.48 \mathrm{mg} \cdot \mathrm{mL}^{-1}$ ) and body weight (11.9 vs $15.7 \mathrm{~g}$ ) 
were lower $(p<0.05)$ in fish reared in variable temperature conditions $(-59$ and $33 \%$ respectively), whereas cortisol (171 vs $23 \mathrm{ng} \cdot \mathrm{mL}^{-1}$ ) and osmolality (392 vs 350 mosm. $\left.\mathrm{kg}^{-1}\right)$ were higher $(\mathrm{p}<0.05)$ in those conditions $(625$ and $+11 \%$ respectively). A strong statistical interaction was found between temperature conditions (T1 vs T2 compared to V1 vs V2)). Differences in plasma cortisol concentration and serum IgM concentration are lower when temperature is variable compared to stable temperature conditions in which differences are more important $(p<0.05)$. Finally, differences in plasma osmolality and weight disappear in fish exposed to variable temperature conditions compared to those exposed to stable rearing temperature conditions.

\subsection{Nodavirus challenge}

\subsubsection{Infectious challenge}

Morbidity (i.e., dead fish or fish displaying whirling disease symptoms; in $\%$ ) in each group following inoculation of nodavirus is shown in Table 5. The cut off limit of the ELISA was calculated based on the analysis of 34 brains (Table 6). The nodavirus was detected in $93.5 \%$ of the brains of diseased fish $(93.5 \%$ were positive in the ELISA at dilution $1: 50$ and $87 \%$ at dilution 1:500) and not in control fish (Table 7 ). The nodavirus was detected in $17.5 \%$ of the fish that survived the challenge with no clinical signs of disease; these fish were considered healthy carriers of the virus.

\subsubsection{Early life husbandry stress and susceptibility to nodavirus}

3.2.2.1 The effect of constant rearing temperature and scrubbing (S1, T1, S2, T2) on fish susceptibility to nodavirus (Table 8). 
A significant temperature effect $(\mathrm{T} 1+\mathrm{S} 1 \mathrm{vs} \mathrm{T} 2+\mathrm{S} 2)$ was found $(\mathrm{p}<0.05)$, whereas scrubbing $(\mathrm{S} 1+\mathrm{S} 2$ vs $\mathrm{T} 1+\mathrm{T} 2)$ had no effect $(\mathrm{p}>0.05)$ on fish susceptibility to nodavirus infection. Fish grown at lower temperature (T1) are more susceptible to nodavirus $(p<0.05)$. To determine whether body weight $(8.7$ $\mathrm{g}$ in low temperature vs $22.6 \mathrm{~g}$ in high temperature) of the fish influenced the challenge results, a second challenge was performed when fish reared at the low temperature had reached a mean weight of $22 \mathrm{~g}$ (T1 at $22 \mathrm{~g}$ compared to T1 at $8.7 \mathrm{~g}$ ). No differences were found (data not shown).

3.2.2.2 The effect of temperature conditions (constant vs variable temperature: treatments $\mathrm{V} 1, \mathrm{~T} 1, \mathrm{~V} 2, \mathrm{~T} 2)$ on fish susceptibility to nodavirus (Table 9).

A significant effect of temperature conditions $(\mathrm{T} 1+\mathrm{T} 2$ vs $\mathrm{V} 1+\mathrm{V} 2)$ on fish susceptibility to nodavirus was found $(p<0.05)$. Fish reared under constant temperature conditions $(\mathrm{T} 1+\mathrm{T} 2)$ were less affected by nodavirus challenge compared to those reared under variable temperature conditions $(V 1+V 2)(p<0.05)$. A statistically significant interaction $(p=0.004)$ was found between constant and variable temperature conditions. Fish grown at constant temperature yielded results consistent with the previous analysis, i.e., susceptibility to nodavirus decreased in high temperature ( $\mathrm{T} 1=7.5$ vs $\mathrm{T} 2=0 \%$ ) $(p=0.016)$.

\section{Discussion}

In the daily practice of aquaculture, stress is difficult to define precisely and usually fish experience combinations of stressors, which can exert short- or long-term effects (reviews in [5, 21, 22]). The fish used in this study were monitored from hatching to six months old juveniles and were submitted to 
controlled single or combined husbandry stressors in an attempt to take into account probable interactions between stress generating factors/conditions. Juvenile sea bass with different early life husbandry-related stress experience displayed differences in both stress and health status. Sea bass juveniles reared during early life in high and constant temperature perform best in terms of stress-related indicators assessed by principle component analysis. Variable water temperature triggered dramatic changes in terms of stress parameters and susceptibility to nodavirus that suggest a strong and prolonged activation of the HPI axis, which corresponds to an allostatic overload [7]. Scrubbing induced some disturbances typical for mild short-term, acute stress, but did not affect plasma cortisol, growth or susceptibility to nodavirus of sea bass. This suggests that scrubbing can be considered as an allostatic load resulting from the cumulative effect of an allostatic state that the fish can cope with.

The limited amount of blood available from these young Dicentrarchus labrax juveniles allowed the measurement of only nine physiological parameters. Indicators of each of the three levels of the stress response (reviews in $[5,23-25]$ ) have been considered. Even with a limited number of parameters, an analysis of combined effects of all these parameters can become extremely difficult. The PCA applied allowed to discriminate the most relevant predictors that determine the integrated physiological response to longterm exposure to common practice husbandry conditions as we applied in a controlled way in the experiments. The second component of the PCA was biologically consistent with plasma cortisol levels, osmolality, serum IgM levels and weight and was subsequently considered as a stress-related component. Plasma cortisol concentration and osmolality trends were opposite to those displayed by serum IgM content and weight. The sampling rank had no effect 
on the experiments performed under constant temperature regimes. Not completely unexpectedly, we found a clear effect for body weight and rank, which is explained by the fact that larger fish are caught more easily than smaller ones. Although this may seem all too obvious, the importance of scoring this bias may not be underestimated, e.g. when tertiary stress parameters such as growth are considered. This finding also highlights the subjective character of sampling procedures despite collective effort for random sampling.

Rearing Dicentrarchus labrax juveniles during their early life at high and stable temperature is better for sea bass as indicated by the parameters selected by PCA: low plasma cortisol levels, normal plasma osmolality (no hemoconcentration), better growth and higher serum IgM content. Differences recorded between Dicentrarchus labrax juveniles subjected to constant high and low temperatures are diminished when the temperature conditions become variable. Variable temperature conditions trigger a drastic increase in plasma cortisol levels, concomitant with hemoconcentration (i.e. increased osmolality), delayed growth, and this suggests a chronic activation of the HPI axis which may represent an allostatic overload. Although within the normal temperature range for a poikilothermic species, sudden shifts in temperature can be stressful. Rotlant et al. [26] reported that a drop in temperature (from 18 to $9^{\circ} \mathrm{C}$ ) triggered in Sparus aurata an increase in cortisol levels for at least 8 days after the beginning of the experiment and correlated with susceptibility to cold water disease. Chen et al. [27] reported a decrease in plasma IgM levels in cold treated (from $25^{\circ}$ to $12^{\circ} \mathrm{C}$ ) Oreochromis aureus, whereas a cold shock of $9^{\circ} \mathrm{C}$ induced significant changes in leucocyte populations and antibody response in carp [28]. However, it has become clear that temperature changes can have profound effects on the immune system that are not related to a stress 
response and may represent adaptive changes related to seasonal temperature variations [29]. It should also be pointed out that as water temperature rises, the $\mathrm{O}_{2}$ carrying capacity of the water decreases and therefore the stress of temperature elevation is probably linked with hypoxic stress. This is partially confirmed by others [30] who reported that a temperature increase from 17 to $26^{\circ} \mathrm{C}$ (within $1 \mathrm{~h}$ ) modified Dicentrarchus labrax haematology reminiscent of a hypoxic situation.

In our experiments, scrubbing did not affect fish weight. Plasma cortisol levels did not change which suggests the occurrence of a "fight or flight" stress response (review in [5]). Others have reported [31] that following 5 minutes scrubbing the tank walls, Dicentrarchus labrax juveniles displayed a secondary stress response comparable to consequences of a severe non-hypoxic exercise, characterized by an increase in several hematological parameters including glycaemia, proteinemia, hematocrit and hemoglobinemia. These data combined with our findings suggest adrenergic function, which in teleosts is very responsive to stress and results in an increase of plasma catecholamines (CAs) within a few minutes. Dicentrarchus labrax juveniles could adapt to this kind of routine husbandry stress (learning response) by a CA induced increase in plasma osmolality and decrease in serum IgM content.

Our experiments show that early life experiences with temperature stress affected plasma cortisol concentrations, serum $\lg M$ and susceptibility to nodavirus in Dicentrarchus labrax. Suppressive effects of cortisol have been reported on both specific and non-specific components of the immune system (review in [32]). High plasma cortisol levels are associated with increasing susceptibility to pathogens, reduced circulating lymphocyte levels and antibody production (reviews in $[4,33,34])$. The mechanisms of cortisol induced 
suppression of the fish immune system are not yet clearly understood but increasing evidence suggests that cortisol may act to inhibit IL-like factors necessary for the differentiation of lymphocytes from their precursors $[35,36]$. Cortisol has also been shown to induce apoptosis in carp B cells [34, 37]. Iguchi et al. [38] reported that fish reared in high density exhibited more elevated cortisol and more suppressed IgM levels. Nagae et al. [39] showed that cortisol specifically suppressed IgM levels in Oncorhynchus masou, whereas Pulsford et al. [40] reported that cortisol suppressed phagocytic activity and proliferative activity of lymphocytes in some species of marine flatfish. Cortisol mediated suppression in phagocytic activity has also been demonstrated in sea bream leucocytes [41]. Comparison of two lines of Salmo salar selected for high and low cortisol response, showed the former to have reduced non-specific immunity and higher susceptibility to pathogens [42].

Fish Nodaviruses cause Viral Encephalopathy and Retinopathy responsible for mortalities in larvae and juveniles of several fish species [43]. Successful experimental transmission of the disease to juveniles has been performed in several fish species including Dicentrarchus labrax [19]. We therefore applied a nodavirus challenge to discriminate effects of different early life stress experiences on disease susceptibility in Dicentrarchus labrax. Fish reared at low temperatures were more affected by virus than those reared in high (optimal) temperature. It is possible that the difference in temperature shift between T1S1 and T2S2 (8 and $2^{\circ} \mathrm{C}$ respectively) could increase the susceptibility of fish to nodavirus. However, an acute shift in temperature is known to induce a hypoxic like stress response (as mentioned previously) and the design of our infectious experiment involved an air exposure of the fish from all the treatments. This air exposure was necessary for the fish inoculation 
minimizing the effect of temperature shift. The IM inoculation has probably induced a more significant stress for all groups. Thus, we can suppose that different mortalities between treatments were mainly due to different early life stress experiences. Morever, fish reared under constant temperature conditions ( $\mathrm{T} 1$ and $\mathrm{T} 2$ ) were less affected by nodavirus challenge compared to those reared under variable temperature conditions (V1 and V2). Stress is known to increase the susceptibility of fish to infectious diseases and challenges with various (bacterial and protozoan) pathogens have been used to assess its effects. Acute stress increased the mortality of Oncorhynchus mykiss inoculated with Aeromonas salmonicida [44]. When Oncorhynchus tshawytscha was challenged with Vibrio anguillarum mortality increased following a transport stressor [45] and fish reared in high density, displayed higher mortality when challenged with Flavobacterium psychrophilum [38].

Our study shows that stress during early life of sea bass has profound effects on stress and health status in juveniles. Changes in four stress predictors validated by the PCA, i.e., plasma cortisol levels, plasma osmolality levels, serum IgM levels and growth rate, could reflect the welfare of the fish in our experiments. These parameters could further provide indirect indication on proper function of non-specific immunity and disease resistance as substantiated by the nodaviral challenge. Also, it appears that, in this species, different husbandry stressors display different immunoendocrine signatures. Scrubbing elicited a "fight or flight" response, which resulted in a "learningadaptation" response. On the other hand temperature conditions (T1and T2 compared to V1 and V2) activated the HPI axis, eliciting high cortisol levels and a decrease in serum IgM content which were related to higher susceptibility to viral challenges. Surprisingly, fish reared at $23^{\circ} \mathrm{C}$ displayed the best profile of 
blood parameters and were less sensitive to nodavirus challenge compared to fish reared at $17^{\circ} \mathrm{C}$, which is in contradiction with a generally accepted - by fish farmers - idea that the optimal temperature for growth would not be optimal for stress and health related parameters.

We believe that multivariate analysis is a powerful tool to discriminate effects of husbandry stressors and could contribute to the establishment of relevant criteria for standards related to welfare, quality and health of reared fish species. Our data fit in very well with the concept of allostatic load and overload which also seem to apply to situations that involve physiological and behavioural responses to husbandry related challenges.

\section{Acknowledgements}

The zootechnical part of the project was conducted within an ASEFAF program in IFREMER Palavas les Flots aquaculture facilities. S. Varsamos was supported by a Marie Curie Individual Fellowship (QLK5-CT2000-52097). The authors wish to thank the personnel of the IFREMER station in Palavas les Flots for their kind assistance.

\section{References}

[1] Selye, H. (1950). Stress and the general adaptation syndrome. British Medical Journal 1, 1383-1392.

[2] Pickering, A.D. (1981). The concept of Biological Stress. In: Stress and Fish. (A.D. Pickering, ed), pp. 1-9. London: Academic Press.

[3] Moberg, G.P. (1985). Biological response to stress: key to assessment of well-being? In: Animal Stress. (G.P. Moberg, ed), pp. 27-49. Betesda: (MD) Am. Physiol. Soc. 
[4] Barton, B.A. \& Iwama, G.K. (1991). Physiological changes in fish from stress in aquaculture with emphasis on the responses and effects of corticosteroids. Annual Review of Fish Diseases 1, 3-26.

[5] Wendelaar Bonga, S.E. (1997). Stress in Fish. Physiological Reviews 77, 591-625.

[6] Pacak, K. \& Palkovits, M. (2001). Stressors specificity of central neuroendocrine responses: implications for stress-related disorders. Endocrine Reviews 22, 502-548.

[7] Mc Ewen, B.S. and Wingfield, J.C. (2003). The concept of allostasis in biology and biomedicine. Hormones and Behavior 43, 2-15.

[8] Duncan, I.J.H. \& Fraser, D. (1997). Understanding animal welfare. In: Animal welfare (M.C. Appleby \& B.O. Hughes, eds), pp. 19-31. Oxfordshire: CABI.

[9] Cooke, M. (2001). Ethical consideration for the production of farmed fish the retailer's viewpoint. In: Farmed fish quality. (S. C. Kestin \& P. D. Warriss, eds), pp. 116-119. Oxford: Blackwell Science Ltd.

[10] Shields, R.J. (2001). Larviculture of marine finfish in Europe. Aquaculture $200,55-88$.

[11] Breuil, G. \& Romestand, B. (1999). A rapid ELISA method for detecting specific antibody level against nodavirus in the serum of the sea bass, Dicentrarchus labrax (L.): application in the screening of spawners in sea bass hatchery. Journal of Fish Diseases 22, 45-52.

[12] Balm, P.H.M., Pepels, S., Helfrich, S. \& Hovens, M.L.M. (1994). Adrenocorticotropic hormone in relation to interrenal function during stress in tilapia (Oreochromis mossambicus). General and Comparative Endocrinology 96, 347-360.

[13] Coeurdacier, J.L., Pepin, J.F., Fauvel, C., Legall, P., Bourmaud, A.F. \& Romestand, B. (1997). Alterations in total protein, IgM and specific activity 
of male and female sea bass (Dicentrarchus labrax L., 1758) sera following injection with killed Vibrio anguillarum. Fish Shellfish Immunology 7, 151-160.

[14] Thiery, R., Arnauld, C. \& Delsert, C. (1999). Two isolates of sea bass, Dicentrarchus labrax, nervous necrosis virus with distinct genomes. Journal of Fish Diseases 22, 201-207.

[15] Breuil, G., Bonami, J.R., Pepin, J.F. \& Pichot, Y. (1991). Viral infection (picorna-like virus) associated with mass mortalities in hatchery-reared sea bass (Dicentrarchus labrax) larvae and juveniles. Aquaculture 97, 109116.

[16] Frerichs, G.N., Rodger, H.D. \& Peric, Z. (1996). Cell culture isolation of piscine neuropathy nodavirus from juvenile sea bass, Dicentrarchus labrax. Journal of General Virology 77, 2067-2071.

[17] Peducasse, S., Castric, J., Thiery, R., Jeffroy, J., Le Ven, A. \& Laurencin, F.B. (1999). Comparative study of viral encephalopathy and retinopathy in juvenile sea bass Dicentrarchus labrax infected in different ways. Disease of Aquatic Organisms 36, 11-20.

[18] Breuil, G., Mouchel, O., Fauvel, C. \& Pepin, J.F. (2001). Sea bass Dicentrarchus labrax Nervous Necrosis virus isolat with distinct pathogenicity to sea bass larvae. Disease of Aquatic Organisms 45, 2531.

[19] Breuil. G., Pepin, J.F., Boscher, S. \& Thiery, R. (2002). Experimental vertical transmission of nodavirus from broodfish to eggs and larvae of the sea bass Dicentrarchus labrax. Journal of Fish Diseases 25, 697-702.

[20] Kramer, C.Y. (1956). Extension of multiple range tests to group means with unequal number of replications. Biometrics 12, 307-310. 
[21] Wedemeyer, G.A. (1997). Effects of rearing conditions on the health and physiological quality of fish in intensive culture. In: Fish Stress and Health in Aquaculture (G.K. Iwama, A.D. Pickering, J.P. Sumpter \& C.B. Schreck, eds), pp. 35-71. Cambridge: Society for Experimental Biology Seminar Series 62, Cambridge University Press.

[22] Pickering, A.D. (1998). Stress responses of farmed fish. In: Biology of farmed fish (K.D. Black \& A.D. Pickering, eds), pp. 222-255. Boca Raton: CRC Press.

[23] Wedemeyer, G.A., Barton, B.A. \& McLeay, D.J. (1990). Stress and acclimation. In: Methods for Fish Biology (C.B. Schreck and P.B. Moyle, eds), pp. 451-489. Bethesda: (MD) Am. Fish. Soc.

[24] Pickering, A. D. \& Pottinger, T. G. (1995). Biochemical effects of stress. In: Environmental and Ecological Biochemistry (P.W. Hochachka and T.P. Mommsen, eds), pp. 349-379. Amsterdam: Elsevier.

[25] Pankhurst, N. \& van der Kraak, G. (1997). Effects of stress on reproduction and growth of fish. In: Fish Stress and Health in Aquaculture (G.K. Iwama, A.D. Pickering, J.P. Sumpter \& C.B. Schreck, eds), pp. 73-93. Cambridge: Society for Experimental Biology Seminar Series 62, Cambridge University Press.

[26] Rotlant, J., Balm, P.H.M., Wendelaar-Bonga, S.E., Perez-Sanchez J. \& Tort, L. (2000). A drop in ambient temperature results in a transient reduction of interrenal $\mathrm{ACTH}$ responsiveness in the gilthead sea bream (Sparus aurata, L.). Fish Physiology and Biochemistry 23, 265-273.

[27] Chen, W.-H., Sun, L.-T., Tsai, C.-L., Song, Y.-L. \& Chang, C.-F. (2002). Cold-stress induced the modulation of catecholamines, cortisol, 
Immunoglobulin M, and leucocyte phagocytosis in tilapia. General and Comparative Endocrinology 126, 90-100.

[28] Engelsma, M.Y., Hougee, S., Nap, D., Hofenk, M., Rombout, J.H.W.M., Muiswinkel, W.B., \& Verburg-Van Kemenade, B.M.L. (2003). Multiple acute temperature stress affects leucocyte populations and antibody responses in common carp, Cyprinus carpio L.. Fish and Shellfish Immunology 15, 397-410.

[29] Saha, N.R., Usami, T. \& Suzuki, Y. (2002). Seasonal changes in the immune activities of commun carp (Cyprinus carpio). Fish Physiology and Biochemistry 26, 379-387.

[30] Hadj Kacem, N., Aldrin, J.F. \& Romestand, B. (1987). Effets immediats d'une augmentation rapide de temperature sur certains parametres sanguins du loup Dicentrarchus labrax (Linne, 1758). Aquaculture 64, 325331.

[31] Hadj Kacem, N., Aldrin, J.F. \& Romestand, B. (1986). Influence immediate du brossage des bacs sur certains parametres sanguins du loup d'elevage Dicentrarchus labrax L. : effet du stress. Aquaculture 59, 53-59.

[32] Harris, J. \& Bird, D.J. (2000). Modulation of the fish immune system by hormones. Veterinary Immunology and Immunopathology 77, 163-176.

[33] Ellis, A.E. (1981). Stress and modulation of defense mechanisms in fish. In: Stress and Fish. (A. D. Pickering, ed), pp. 147-170. London: Academic Press.

[34] Weyts, F.A.A., Cohen, N., Flik, G. \& Verburg-van Kemenade, B.M.L. (1999). Interactions between the immune system and the hypothalamopituitary-interrenal axis in fish. Fish and Shellfish Immunology 9, 1-20. 
[35] Kaattari, S.L. \& Tripp, R.A. (1987). Cellular mechanisms of glucocorticoid immunosuppression in salmon. Journal of Fish Biology 31 (suppl. A), 129132.

[36] Engelsma, M.Y., Huising, M.O., Muiswinkel, W.B., Flik, G., Kwang, J., Savelkoul, H.F.J. \& Verburg-Van Kemenade, B.M.L. (2002). Neuroendocrine-immune interactions in fish: a role for interleukin 1. Veterinary Immunology and Immunopathology 87, 467-479.

[37] Weyts, F.A.A., Flik, G., Rombout, J.H., \& Verburg-van Kemenade, B.M.L (1998). Cortisol induces apoptosis in activated B cells, not in other lymphoid cells of the common carp, Cyprinus carpio L.. Developmental \& Comparative Immunology 22, 551-562.

[38] Iguchi, K., Ogawa, K., Nagae, M. \& Ito, F. (2003). The influence of rearing density on stress response and disease susceptibility of ayu (Plecoglossus altivelis). Aquaculture 220, 515-523.

[39] Nagae, M., Fuda, H., Ura, K., Kawamura, H., Adachi, S., Hara, A. \& Yamauchi, K. (1994). The effect of cortisol administration on blood plasma immunoglobulin $\mathrm{M}(\mathrm{IgM})$ concentrations in masu salmon (Oncorhynchus masou). Fish Physiology and Biochemistry 13, 41-48.

[40] Pulsford, A.L., Crampe, M., Langston, A. \& Glynn, P.J. (1995). Modulatory effects of disease, stress, copper, TBT and vitamin E on the immune system of flatfish. Fish and Shellfish Immunology 5, 631-643.

[41] Esteban, M.A., Rodriguez, A., Ayala, A.G. \& Meseguer, J. (2004). Effects of high doses of cortisol on innate cellular immune response of sea bream (Sparus aurata L.). General and Comparative Endocrinology 137, 89-98. 
[42] Fevolden, S.E., Nordmo, R., Refstie T., \& Roed, K.H. (1993). Disease resistance in Atlantic salmon (Salmo salar) selected for high or low responses to stress. Aquaculture $109,215-224$.

[43] Office International des Epizooties (OIE), World Organization for Animal Health (1995). Diagnostic Manual of Aquatic Animal Diseases. OIE Fish Disease Commission, Paris.

[44] Angelidis, P., Baudin-Laurencin, F. \& Youinou, P. (1987). Stress in rainbow trout, Salmo gairdneri: effects upon phagocyte chemiluminescence, circulating leucocytes and susceptibility to Aeromonas salmonicida. Journal of Fish Biology 31 (suppl. A), 113-122.

[45] Maule, A.G., Tripp, R.A., Kaattari, S.L. and Schreck, C.B. (1989). Stress alters immune function and disease resistance in chinook salmon (Oncorhynchus tshawytscha). Journal of Endocrinology 120, 135-142. 
Fig. 1. Output of the PCA (measurements from 90 fish and six treatments (S1, S2, T1, T2, V1, V2)). The first three components accounted for $72 \%$ of the variability of the data (24, 26 and $22 \%$ for components 1,2 and 3 respectively).
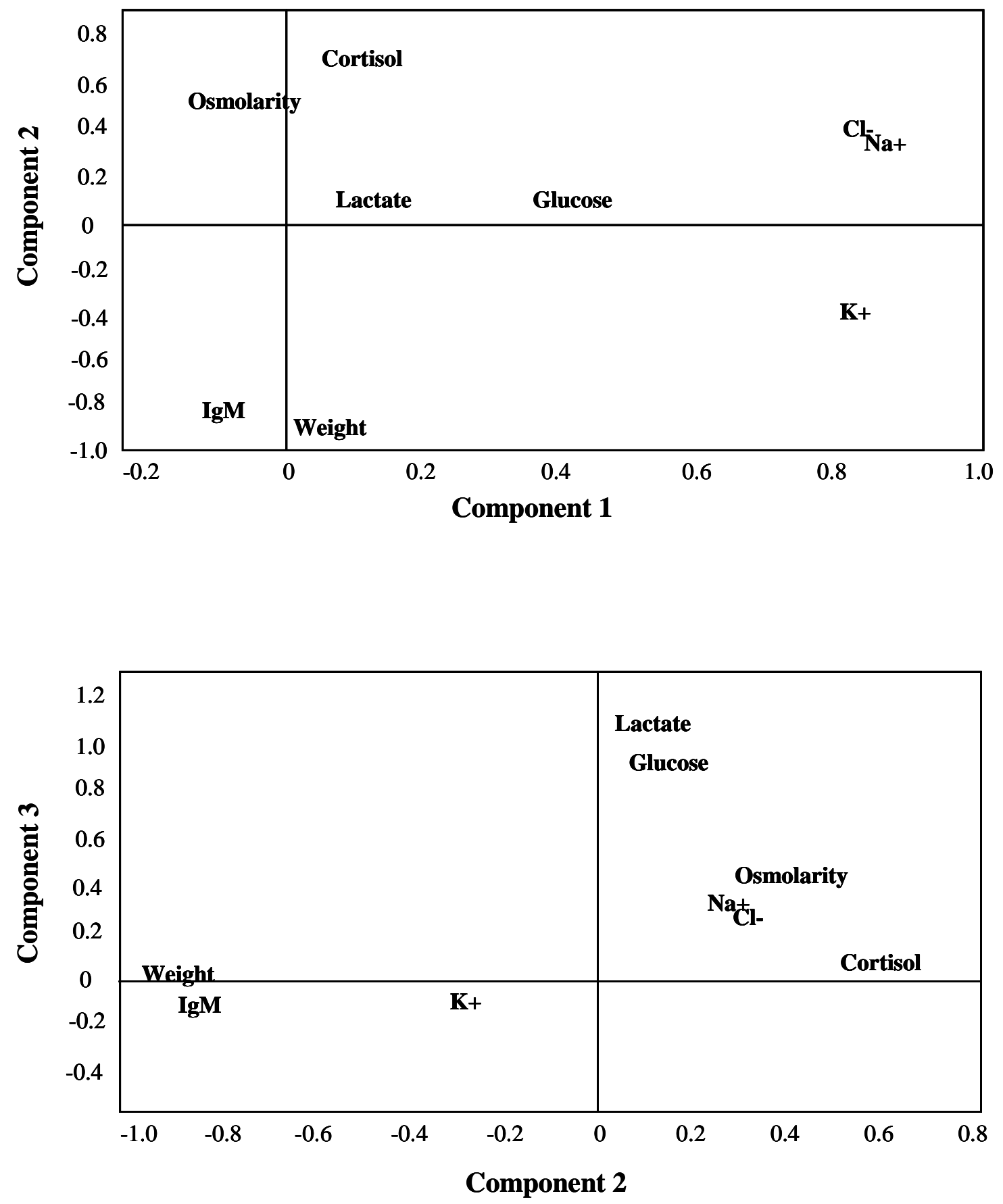
Table 1. Principal Component Analysis (PCA) output for the data concerning the physiological parameters considered in this study, from all treatments ( $\mathrm{T} 1$, T2, S1, S2, V1, V2).

\begin{tabular}{|c|c|c|c|}
\hline \multirow{2}{*}{ PCA } & \multicolumn{3}{|c|}{ Loadings on the three first components generated by the } \\
\hline Variable & Component 1 & Component 2 & Component 3 \\
\hline IgM & $-0,095680$ & $-0,849170$ & $-0,132398$ \\
\hline Osmolality & $-0,052167$ & 0,412344 & 0,446737 \\
\hline $\mathrm{Na}^{+}$ & 0,842242 & 0,303782 & 0,369930 \\
\hline $\mathrm{Cl}^{-}$ & 0,845573 & 0,287147 & 0,308112 \\
\hline Glucose $^{*}$ & 0,352268 & 0,092917 & 0,835798 \\
\hline $\mathrm{K}^{+}$ & 0,776210 & $-0,307645$ & $-0,085431$ \\
\hline Lactate & 0,117122 & 0,051158 & 0,937199 \\
\hline Weight & 0,035917 & $-0,886823$ & $-0,045856$ \\
\hline Cortisol & 0,102613 & 0,622661 & $-0,084760$ \\
\hline
\end{tabular}


Table 2A. Effects of various treatments on serum IgM concentration, plasma osmolality, plasma cortisol concentration and body weight at the end of the experiment (mean and standard deviation).

\begin{tabular}{|c|c|c|c|c|c|c|c|c|c|c|c|c|}
\hline Treatment & $\begin{array}{r}\mathrm{S} \\
\text { mean }\end{array}$ & sdev & $\begin{array}{r}\top \\
\text { mean }\end{array}$ & 1 & $\begin{array}{r}\mathrm{S} \\
\text { mean }\end{array}$ & sdev & mean & 2 & mean & 1 & mean & sdev \\
\hline $\begin{array}{l}\text { Serum IgM } \\
\left(\mathrm{mg} \cdot \mathrm{ml}^{-1}\right)\end{array}$ & 0.53 & 0.16 & 0.54 & 0.22 & 1.76 & 0.43 & 2.42 & 0.51 & 0.74 & 0.45 & 1.12 & 0.65 \\
\hline $\begin{array}{c}\text { Plasma } \\
\text { osmolarity } \\
\left(\mathrm{mosm} \cdot \mathrm{kg}^{-1}\right)\end{array}$ & 357 & 10 & 346 & 6 & 372 & 16 & 352 & 12 & 409 & 26 & 374 & 36 \\
\hline Body weight (g) & 8.6 & 0.5 & 8.7 & 0.9 & 22.7 & 5.9 & 22.5 & 3.5 & 11.0 & 2.4 & 12.8 & 4 \\
\hline 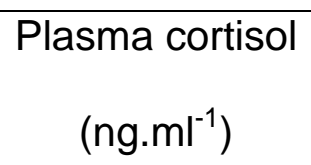 & 21 & 23 & 40 & 54 & 13 & 30 & 7 & 6 & 186 & 56 & 155 & 45 \\
\hline
\end{tabular}

Table 2B. Mean values of serum IgM concentration, plasma osmolality, plasma cortisol concentration and body weight in treatments combinations considered for statistical analysis

\begin{tabular}{|c|c|c|c|c|c|c|c|}
\hline & S1+T1 & S2+T2 & T1+T2 & $\mathrm{S} 1+\mathrm{S} 2$ & V1+T1 & $\mathrm{V} 2+\mathrm{T} 2$ & $\mathrm{~V} 1+\mathrm{V} 2$ \\
\hline Serum IgM $\left(\mathrm{mg} \cdot \mathrm{ml}^{-1}\right)$ & 0.54 & 2.1 & 1.48 & 1.14 & 0.64 & 1.77 & 0.93 \\
\hline $\begin{array}{c}\text { Plasma osmolarity } \\
\left(\text { mosm. } \mathrm{kg}^{-1}\right)\end{array}$ & 352 & 362 & 349 & 365 & 378 & 363 & 392 \\
\hline Body weight (g) & 8.7 & 22.6 & 15.7 & 15.6 & 9.9 & 17.6 & 11.9 \\
\hline $\begin{array}{c}\text { Plasma cortisol } \\
\left(\mathrm{ng} \cdot \mathrm{ml}^{-1}\right)\end{array}$ & 30 & 10 & 23 & 17 & 113 & 81 & 171 \\
\hline
\end{tabular}


Table 3. MANOVA summary: effects of constant temperatures (high and low) and scrubbing (treatments S1, T1, S2, T2) on serum IgM concentration, plasma osmolality, plasma cortisol concentration and weight. (* indicates significant differences).

\begin{tabular}{|c|c|c|c|c|}
\hline General MANOVA & \multicolumn{5}{|c|}{ 1-Rank / 2- Constant temperature / 3-Scrubbing } \\
\hline Effect of 1, 2, 3 & $\lambda$ (Wilks) & DF1 & DF2 & $P$ \\
\hline 1 & 0,622904 & 8 & 58 & 0,071596 \\
\hline 2 & $0,114591^{\star}$ & $4^{*}$ & $29^{\star}$ & $0,000000^{\star}$ \\
\hline 3 & $0,656405^{\star}$ & $4^{*}$ & $29^{\star}$ & $0,013361^{\star}$ \\
\hline 1 and 2 & 0,784398 & 8 & 58 & 0,494369 \\
\hline 1 and 3 & 0,918342 & 8 & 58 & 0,957107 \\
\hline 2 and 3 & 0,846282 & 4 & 29 & 0,287094 \\
\hline 1,2 and 3 & 0,896194 & 8 & 58 & 0,911266 \\
\hline
\end{tabular}


Table 4. MANOVA summary: effects of temperature conditions (constant vs variable temperature: treatments $\mathrm{V} 1, \mathrm{~T} 1, \mathrm{~V} 2, \mathrm{~T} 2$ ) on sea bass (Dicentrarchus labrax) juveniles on serum IgM concentration, plasma osmolality, plasma cortisol concentration and weight.

( ${ }^{*}$ indicates significant differences).

\begin{tabular}{|c|c|c|c|c|}
\hline \multirow{2}{*}{$\begin{array}{c}\text { General } \\
\text { MANOVA }\end{array}$} & \multicolumn{4}{|c|}{ 1-Rank / 2-Constant temperature / 3- Variable } \\
\hline Effect of 1, 2, 3 & $\lambda$ (Wilks) & DF1 & DF2 & P \\
\hline 1 & $0,674196^{*}$ & $8^{*}$ & $76^{\star}$ & $0,049189^{\star}$ \\
\hline 2 & $0,292530^{*}$ & $4^{*}$ & $38^{\star}$ & $0,000000^{\star}$ \\
\hline 3 & $0,227732^{\star}$ & $4^{\star}$ & $38^{*}$ & $0,000000^{\star}$ \\
\hline 12 & 0,805864 & 8 & 76 & 0,384449 \\
\hline 13 & 0,794223 & 8 & 76 & 0,334471 \\
\hline 23 & 0,323508 & 4 & 38 & 0,000000 \\
\hline 123 & 0,779832 & 8 & 76 & 0,278256 \\
\hline
\end{tabular}

Table 5. Percentage morbidity following challenge with nodavirus from different treatments and from non inoculated (control) fish. (Data from duplicate tanks)

\begin{tabular}{|c|c|c|c|c|c|c|c|}
\hline treatment & S1 & T1 & S2 & T2 & V1 & V2 & Control \\
\hline Tank 1 & $15 \%$ & $5 \%$ & $0 \%$ & $0 \%$ & $15 \%$ & $0 \%$ & $0 \%$ \\
\hline Tank 2 & $10 \%$ & $10 \%$ & $0 \%$ & $0 \%$ & $15 \%$ & $15 \%$ & $0 \%$ \\
\hline
\end{tabular}


Table 6. Determination of the cut off limit of the ELISA (optical density (OD) values of 34 different seronegative sea bass (Dicentrarchus labrax) juveniles brains diluted to 1:500. According to the Bienaymé-Tchebicheff inequality, the probability for OD value $>m+k \sigma$ is $1 / k^{2}$ (For $k=5$ the probability is 0.04 ). The samples were significantly $(P=0.05)$ different from the control when the $O D$ values were higher than 0.058 (cut off limit of the ELISA).

\begin{tabular}{|c|c|c|c|}
\hline Number of & Mean OD values $(\mathrm{m})$ & Standard error $(\sigma)$ & Cut off limit $(\mathrm{m}+5 \sigma)$ \\
\hline 34 & 0.008 & 0.010 & 0.058 \\
\hline
\end{tabular}

Table 7. Antigen detection in the brain of sea bass (Dicentrarchus labrax) from diseased, non diseased (surviving fish) and control fish (non injected fish) following challenge with nodavirus.

\begin{tabular}{|c|c|c|c|}
\hline ELISA response & $\begin{array}{l}\text { Diseased fish } \\
\qquad(n=31)\end{array}$ & $\begin{array}{l}\text { Non diseased } \\
\qquad(n=93)\end{array}$ & $\begin{array}{l}\text { Control } \\
(n=68)\end{array}$ \\
\hline $\begin{array}{c}\text { Positive at dilution } \\
1: 500\end{array}$ & $27(87 \%)$ & $7(7.5 \%)$ & $0(0 \%)$ \\
\hline Positive at dilution 1:50 & $29(93.5 \%)$ & $17(17.5 \%)$ & $0(0 \%)$ \\
\hline Negative & $2(6.5 \%)$ & $76(81.8 \%)$ & $\begin{array}{c}68 \\
(100 \%)\end{array}$ \\
\hline
\end{tabular}


Table 8. Two ways Analysis of variance : effect of temperature and scrubbing between constant temperature treatments ( $\mathrm{S} 1, \mathrm{~T} 1, \mathrm{~S} 2, \mathrm{~T} 2)$ on sea bass (Dicentrarchus labrax) juveniles susceptibility to nodavirus (data: percent of morbidity following challenge with nodavirus). (* indicate significant differences).

\begin{tabular}{|l|c|c|c|}
\hline Source of variation & DF & F & P \\
\hline Constant temperature & 1 & 37.471 & $0.004^{*}$ \\
\hline Scrubbing & 1 & 2.828 & 0.168 \\
\hline Constant temperature x Scrubbing & 1 & 2.8280 & 0.168 \\
\hline Residual & 4 & & \\
\hline Total & 7 & & \\
\hline
\end{tabular}

Table 9. Two ways Analysis of variance: effect of temperature conditions (constant vs variable temperature: treatments $\mathrm{V} 1, \mathrm{~T} 1, \mathrm{~V} 2, \mathrm{~T} 2$ ) on sea bass (Dicentrarchus labrax) juveniles susceptibility to nodavirus (data: percent of morbidity following challenge with nodavirus). (* indicates significant differences).

\begin{tabular}{|l|c|c|c|}
\hline \multicolumn{1}{|c|}{ Source of variation } & DF & F & P \\
\hline Constant temperature & 1 & 2.380 & 0.198 \\
\hline Variable temperature & 1 & 8.744 & $0.042^{\star}$ \\
\hline Constant temperature x Variable temperature & 1 & 33.471 & $0.004^{\star}$ \\
\hline Residual & 4 & & \\
\hline Total & 7 & & \\
\hline
\end{tabular}

